This is an electronic preprint version of a paper published in the Proceedings of the Aristotelian Society, Vol. CXIV, Part 2

\title{
Fitting Belief
}

Conor McHugh

\begin{abstract}
Beliefs can be correct or incorrect, and this standard of correctness is widely thought to be fundamental to epistemic normativity. But how should this standard be understood, and in what way is it so fundamental? I argue that we should resist understanding correctness for belief as either a prescriptive or an evaluative norm. Rather, we should understand it as an instance of the distinct normative category of fittingness for attitudes. This yields an attractive account of epistemic reasons.
\end{abstract}

Introduction. I begin with two plausible claims. The first is:

(a) Belief has a standard of correctness.

That is, beliefs can be correct or incorrect, depending on whether they satisfy a certain standard. It is very widely held that this standard is $\underline{t r u t h}$ : the belief that $\underline{p}$ is correct when $\underline{p}$ is true and incorrect when $\underline{p}$ is false. Some philosophers have suggested that the standard is not truth but knowledge (Smithies 2012). In most of what follows it won't matter whether the standard is truth or knowledge. When that is so I will sometimes talk, for brevity, as though the standard is truth. Strictly I mean to be neutral.

The second plausible claim is:

(b) Belief's standard of correctness is fundamental to epistemic normativity.

By 'fundamental' I mean that the standard of correctness helps to explain the extensions of many (other) epistemic normative properties. For example, it is often thought that a belief is epistemically justified when and because it is, in some sense, sufficiently likely to be correct, or a sufficiently good attempt at correctness. This is rough, but I hope it makes the general idea, which is widespread, ${ }^{1}$ clear enough for my purposes.

The normative property I will focus on is that of being an epistemic reason. So, according to (b), a consideration's being an epistemic reason for a certain belief is explained by some relation between that consideration and the putative correctness of the belief.

In what follows I will assume that (a) and (b) are true. This raises two questions which I want to address:

\footnotetext{
${ }^{1}$ E.g. Bonjour (1985), Goldman (1999), Wedgwood (2002), Boghossian (2003), Lynch (2004), Alston (2005), Sosa (2007).
} 
First question: $\quad$ What is the nature of this standard of correctness?

Second question: How does it ground epistemic normativity? In particular, how does it explain why certain considerations are epistemic reasons for certain beliefs?

So, can we say something to characterise the property of correctness that true beliefs have? And can we, for example, articulate some principle, linking the standard of correctness for belief to epistemic reasons, that captures how certain considerations get to be epistemic reasons?

Good answers to these questions should satisfy the following desiderata:

(D1) They should cohere with plausible claims in the theory of normativity;

(D2) They should contribute to (or at least be compatible with) an explanation of the dominance of evidence among reasons for belief.

What do I mean by 'dominance'? It is sometimes held that only evidence can give reasons for (or against) belief. But that's controversial. We might retreat to the claim that only evidence can give epistemic reasons. But that's to say too little. Even if only evidence can give epistemic reasons, it doesn't follow that these reasons have any special standing relative to other putative reasons (e.g. prudential) for and against belief. But they do seem to have such a standing. It seems that believing in the absence of sufficient evidence always makes you irrational, or criticisable, in an overall sense. The evidence isn't just one set of reasons, to weigh up against others, and to potentially be outweighed, in reasoning about what to believe. You have overall sufficient reason to believe only if you have, specifically, sufficient evidential reasons.

In what follows I will examine two popular accounts of the standard of correctness of belief, and find that they do badly by D1 and D2. I will propose and defend a neglected alternative.

What is Correctness for Belief? The standard of correctness for belief has been understood by some philosophers to be a prescriptive norm, to the effect that you may not believe what's false, whereas you may or ought to believe what's true. ${ }^{2}$ Call this the prescriptive view. Others have understood the standard to be a value. These philosophers hold that true belief is somehow good, and/or false belief bad. ${ }^{3}$ Call this the evaluative view.

These views can be understood in different ways. They can be understood as giving an account of what correctness for belief $\underline{i s}$ - of the property that we attribute to beliefs when we say they are correct. For example, for a belief to be correct $\underline{i s}$ for it to be the belief you

\footnotetext{
2 That there is such a prescriptive norm is defended by Boghossian (2003), Shah (2003) and Whiting (2010).

${ }^{3}$ That true belief is valuable is defended by Bonjour (1985), Goldman (1999), Lynch (2004), Alston (2005), Sosa (2007), Fassio (2011), McHugh (2012).
} 
ought to have, or for it to be a good belief to have. Or, they can be understood as claiming that beliefs' being correct or incorrect is explained by their having a distinct prescriptive or evaluative property. For example, what makes it correct to believe the truth is that this is what you ought to believe, or what is good to believe. Either way, on these views, when it comes to answering the second question, what does the real normative work is some prescriptive or evaluative property, and not correctness as such.

Problems for the Prescriptive View. The prescriptive view's answer to the first question is that the standard of correctness for belief is a prescriptive norm. How does it answer the second question? Presumably, by appealing to some principle linking prescriptive norms to reasons. For example, we might say that evidence that you ought to do something is a reason to do that thing (Kearns and Star 2009). If the truth is what you ought to believe, this would explain why evidence for $\underline{p}$ is a reason to believe $\underline{p}$.

However, this assumes that the standard of correctness for belief is an ought - a requirement to believe truths. This is not especially plausible. Many truths are beyond our ken, many are uninteresting, and there are uncountably more truths than we could ever get around to believing. We are surely not doing something wrong by failing to believe all these truths. Even if the supposed requirement to believe truths was restricted in some way, in order to avoid this problem, further problems arise when we consider propositions whose truth-value can be changed by our believing them, as with so-called 'blindspot' propositions, and selffulfilling and self-falsifying beliefs. In certain such cases, a requirement to believe what's true is unsatisfiable (Bykvist and Hattiangadi 2007; McHugh 2012).

Fortunately, prescriptive norms can be merely permissive. The most plausible version of the prescriptive view holds that the correctness norm is like this: it says that we may believe what's true, and we may not believe what's false (Whiting 2010).

This version of the prescriptive view avoids some of the problems mentioned above. However, I think it fails D2. I think it fails to explain why evidence for a proposition is a reason to believe that proposition at all, and a fortiori fails to explain why such reasons are dominant. $^{4}$

On the face of it, something's being merely permitted — not forbidden — or evidence for this, doesn't seem to be or explain the existence of any positive reason to do this thing. For example, you may stir your tea clockwise, but this doesn't seem to indicate or make it the case that you have any reason to do so.

The defender of the prescriptive view might insist that, appearances notwithstanding, mere permissions (or evidence of them) do, at least sometimes, give rise to reasons. In particular, they might insist, the permission to believe truths does this. But then more difficulties follow. These stem from the point that, if believing the false is forbidden and believing the truth is merely permitted, then withholding on (suspending judgment about) the truth must also be

\footnotetext{
${ }^{4}$ The claim that evidence for $\underline{p}$ is a reason to believe $\underline{p}$ may need qualification. Perhaps evidence for $\underline{p}$ must be accessible to an agent in order for it to be a reason for her to believe $p$. I will assume that any such accessibility requirement is met in the cases I discuss. I will return to other possible qualifications below.
} 
permitted. If it were not, then, of the three available outright doxastic attitudes to a proposition $\underline{p}$, only one would be permitted. But if only one option is permitted, then that option is required. So, on pain of collapsing into the implausible view on which belief in truths is required, the permissive version of the prescriptive view must allow that withholding on truths is permitted. Withholding on truths thus has the same status, with respect to the correctness norm so construed, as true belief. ${ }^{5}$

I think this is implausible in itself, since withholding on a truth is not correct in the same way that believing it is. But, given (b), it also seems to have the odd consequence that, if evidence for $\underline{p}$ is a reason to believe $\underline{p}$, then it is also a reason to withhold on $\underline{p}-$ a reason in just the same sense, and of the same strength. That's because, if there is some principle linking permission to reasons, such that a norm permitting belief in truths makes evidence for $\underline{p}$ count as a reason to believe $\underline{p}$, then, if that norm also permits withholding on truths, that same principle will make evidence for $\underline{p}$ equally count as a reason to withhold on $\underline{p}$.

So, on this view, evidence for $\underline{p}$ won't favour believing over withholding. But, intuitively, evidence for $\underline{p}$ is a reason for, specifically, believing $\underline{p}$.

In response, it might be suggested that evidence for $\underline{p}$ is a reason to believe $\underline{p}$ only when you are aiming to make up your mind about whether $\underline{p}$, and that the prescriptive view can explain why it is a reason in these circumstances. To withhold would be to frustrate the aim of making up your mind. So, perhaps evidence for $\underline{p}$ becomes a reason for, specifically, believing $\underline{p}$, because it is the only way you can permissibly satisfy your aim.

This suggestion seems to presuppose that, by adopting the aim of making up your mind about whether $\underline{p}$, you give yourself a reason to satisfy that aim. That would be surprising: we cannot typically give ourselves reasons to do things just by aiming to do them. What's more, this suggestion faces a dilemma. If satisfying the aim remains something that it is merely permissible to do, then the foregoing argument applies: evidence for $\underline{p}$ doesn't seem to favour permissibly satisfying the aim over permissibly not doing so by withholding. On the other hand, if we suppose that, once you have some aim, you ought to satisfy it, then the present suggestion amounts to a restricted version of the obligation view, and runs into problems previously mentioned. You can, for example, aim to make up your mind about propositions that would be false if you believed them. On this view, you thereby give yourself unsatisfiable requirements.

So it seems that the prescriptive view cannot plausibly explain why evidence gives reasons for belief. On this view, even a conclusive proof of $\underline{p}$ by itself gives no reason at all to believe $\underline{p}$. If there are ever positive reasons for believing anything, they must be non-evidential. So it looks like this view can't explain the dominance of evidential reasons; it fails D2.

The prescriptivist might deny that this is a problem. They might embrace the conclusion that evidence for $\underline{p}$ by itelf never gives or entails any reason to believe $\underline{p}$. They might insist that you have such a reason only when you have, in addition to the evidence for $\underline{p}$, some reason to make up your mind about whether $\underline{p}$. Sufficient evidence is a necessary condition on having sufficient reason to believe, they might claim, even though the evidence by itself is no reason to believe. ${ }^{6}$ This is not dominance as I characterised it, but it's similar.

\footnotetext{
${ }^{5}$ I defend this further in McHugh (2012).

${ }^{6}$ Whiting (2013) defends something similar.
} 
What is the character of reasons for belief, on the proposed view? Perhaps they are hybrid, both evidential and non-evidential. Alternatively, perhaps evidence is a mere enabler (Dancy 2004) for there being a reason, the reason itself being given by the non-evidential consideration that favours making up your mind. ${ }^{7}$ Either way, it is fair to say that we have here an unorthodox view of reasons for belief. ${ }^{8}$ It seems to me contrary to our ordinary way of thinking about them.

This view also implies surprising things about cases in which people hold beliefs based on excellent evidence, but on matters about which they in fact have no reason to make up their mind. For example, I have no reason to make up my mind about the colour of the car that just passed my window, but, having seen it, I now have a belief about this based on impeccable evidence. The present suggestion entails that this belief of mine is one for which I have no reasons. That seems false.

Nor is it clear how (something resembling) dominance is explained. On the proposed view, non-evidential considerations can be reasons for belief, or parts of them. Why, then, can't they give sufficient reason for belief, even in the absence of sufficient evidence? The idea might be this: if you lack sufficient evidence, then you lack sufficient reassurance that belief is permissible. But, in general, it's not clear that the absence of sufficient evidence that something is permissible entails that you lack sufficient reason to do it. In a situation where you have only limited evidence about which of the available options is permissible - a possibility this view must surely allow for - can't you still have sufficient reason to take one of them?

The prescriptive view also faces problems when it comes to D1. It is highly plausible that what you ought and may do are determined by what reasons you have: if you ought to $\varphi$, that's because you have most or decisive reason to $\varphi$, and if you may $\varphi$, that's because you lack most or decisive reason not to $\varphi$ (Schroeder 2007, Ch. 7). ${ }^{9}$ Given this, the prescriptive view implies that you never have most or decisive reason not to believe a truth. Since evidence can be partial and misleading, this would be a surprising result.

Secondly, we seem to face an explanatory circularity. We are assuming, by (b), that what considerations are epistemic reasons is explained by a connection between those considerations and the standard of correctness for belief. On the prescriptive view, this amounts to the claim that evidence gives reasons because you may believe the truth. But, given the highly plausible idea just mentioned, this seems backwards: if you may believe the truth, that is because your reasons stack up accordingly.

These points aren't decisive. It can be insisted that you never have most or decisive reason not to believe truths. The claim that what you ought and may do are determined by your reasons can be denied. But these are controversial commitments to take on.

\footnotetext{
${ }^{7}$ Couldn't it be claimed that the evidence is the reason for belief and the non-evidential consideration is the mere enabler? I find it hard to see how. The non-evidential consideration is a reason to make up your mind. How then, on this view, could it be a mere enabler for something else's being a reason to make up your mind in the way that is permissible? It is part of what favours making up your mind in the permissible way, not just a background condition on something else's favouring this.

${ }^{8}$ See, for example, the Introduction and contributions to Reisner and Steglich-Petersen (2011).

${ }^{9}$ Plausibly, the set of reasons relevant to determining what you ought and may do is restricted. In particular, though evidence gives reasons for belief, the mere existence of conclusive evidence for $\underline{p}$ does not make it the case that you ought to believe $\underline{p}$. See also n. 4 .
} 
Problems for the evaluative view. The evaluative view answers the first question by saying that true belief is somehow good, and false belief bad. How does it answer the second question? It would be natural to appeal to a principle to the effect that, when ping would promote or instantiate some value, or when there is evidence for this, there are thereby reasons for ping. This would explain why evidence for $\underline{p}$ is a reason for, specifically, believing $\underline{p}$.

Nonetheless, I think the evaluative view struggles to satisfy D2. There are many ways in which a belief might be valuable, regardless of whether it is true. It might make you happy, for example. So, unless the value of true belief is infinite, it's hard to see why reasons explained by other values couldn't compete against, and sometimes outweigh, reasons explained by the value of truth.

It might be said that epistemic assessment is uniquely concerned with one fundamental value, namely that of true belief, and so reasons explained by other values are irrelevant to it. Maybe so. But then we need an explanation of why this kind of assessment dominates the overall assessment of belief.

Perhaps this has something to do with the nature of belief: truth-orientated assessment is proper to belief, it might be said, in a way that other sorts of assessment aren't. Here we might invoke the distinction between attributive and predicative good - between goodness qua thing of a certain kind and goodness simpliciter. We could then say that truth is what makes a belief good qua belief, even if other things can make a belief good in other ways. Belief, on this view, is a goodness-fixing kind, comparable to the kind knife. Just as there is such a thing as a good knife, and the standard for being a good knife is fixed by the nature of knives, so there is such a thing as a good belief, and the standard for being a good belief (truth) is fixed by the nature of belief. ${ }^{10}$ Epistemic assessment is the assessment of beliefs $\underline{a s}$ beliefs, and this is why it dominates the overall assessment of belief.

While attractive, I don't think this view satisfies D2. If $\underline{x}$ is an $\underline{F}$, whether $\underline{x}$ is a good $\underline{F}$ dominates other considerations in assessing $\underline{x}$ as an F. But it need not dominate other considerations in assessing $\underline{x}$, full-stop; nor in assessing an agent's choice of $\underline{x}$. For example, you might have better reasons to get a cheap car than a good one. You need not be irrational or criticisable in any way for choosing the cheap one. So it's not clear, on this view, why you should be irrational or criticisable for forming a belief without sufficient evidence, and thus one that risks being bad qua belief, if there are strong considerations of some other sort that favour doing so - for example, that it would make you happy. ${ }^{11}$

\footnotetext{
${ }^{10}$ McHugh (2012). For the notion of a goodness-fixing kind see Thomson (2008).

${ }^{11}$ A suggestion: the goodness of $x$ qua $F$ does dominate other considerations in assessing (the choice of) $\underline{x}$, when $\underline{F}$ is the most general relevant goodness-fixing kind. When choosing a car, perhaps the most general goodnessfixing kind is not $\underline{\text { car }}$, but something like choice or action. The choice of the cheap car might be good qua choice, or qua action. One worry here is that the notion of the generality of a goodness-fixing kind might prove hard to spell out in a way that makes the proposed view plausible. A second, related worry is that, when you believe something, belief might not be the most general relevant goodness-fixing kind. Perhaps acceptance or
} 
So much for D2. What about D1? The evaluative view appears to sit badly with the currently popular view that what's good is what's correct or fitting to value (Scanlon 1998). Together, they would entail that true beliefs are correct because it is correct to value them (qua belief, perhaps). While not exactly circular, it seems odd to explain correctness for beliefs in terms of correctness for other attitudes. Of course, one might reject the fitting-attitudes account of value. But this is not an insignificant commitment. ${ }^{12}$

A second worry here is this: it's prima facie odd to suppose that something's being good also makes it correct. These seem like very different properties. Pleasure is good, but it's not correct; good knives are not also correct knives. Of course, hedonic qualities and knives don't have standards of correctness, so are not apt to be correct or incorrect. But that just seems to support the idea that correctness isn't a species of goodness. It seems natural to say that if true beliefs are good that is because they are correct, rather than the converse.

This raises a general worry about the motivation for the evaluative view, and indeed of the prescriptive view. Why suppose that the standard of correctness for belief must be understood in terms of some seemingly distinct evaluative or prescriptive property? Isn't correctness itself the property we are looking for? Perhaps the thought is that correctness is not a distinct property at all. Or perhaps it is that correctness is not normative, so the standard of correctness for belief needs some other property to give it its normative force. But I think these views are mistaken.

Correctness as Fittingness. ${ }^{13}$ If correctness for belief isn't explained or constituted by a prescriptive norm or a value, how should we understand it? I propose that it is an instance of the familiar property of correctness, or fittingness, for an attitude. I propose that fittingness is a distinct normative property in its own right, neither prescriptive nor evaluative.

Not just belief, but also many other attitudes, can be correct or incorrect, fitting or unfitting. When you want a potted plant in your office, admire Mandela, regret a thoughtless remark, or fear the onrushing tiger, your attitude can be fitting or unfitting, depending on the features of its object. It's correct, fitting, appropriate or right - these terms can all be used to pick out the same property, though they need not always be used in this way - to admire Mandela and fear the tiger. It's incorrect, unfitting, inappropriate or wrong to admire Idi Amin and fear the onrushing kitten. ${ }^{14}$

Thus, desire, admiration, regret and fear each set a standard that must be met in order for the attitude to be fitting or correct when held towards a given object. For example, the standard of fittingness for admiration specifies the features that a given object must have in order for admiration of it to be fitting. These features make the object fit to admire, worthy of

propositional attitude is, or mental state, or thing. But I can't pursue this here. Thanks to Alex Gregory for the suggestion.

${ }^{12}$ Way (2013) gives arguments for a fitting-attitudes account of value over a value-first account of reasons.

${ }^{13}$ Many of the ideas I present in this section and the next have been developed in collaboration with Jonathan Way. We defend some of them in more detail in McHugh and Way (m.s.).

${ }^{14}$ For the notion of fittingness or correctness applied to such attitudes, see Brentano (1889/1969), Wiggins (1987), Thomson (2008), Chappell (2012). My account here bears some similarities to Thomson's. 
admiration, or, as we say, admirable. This standard is, very plausibly, internal to the attitude. It is in virtue of what admiration $\underline{i s}$ that the qualities exhibited by Mandela make a person admirable whereas those exhibited by Amin do not.

Similarly, I claim, the attitude of belief sets truth as the standard that a proposition must meet in order for it to be a fit object of that attitude - in order for it to be fitting or correct to believe the proposition.

For an attitude to be fitting is for it to have a normative property. But it is not fitting because you ought to hold it, or because you $\underline{\operatorname{may}}$ hold it, or because it would be good if you held it. Fittingness, I maintain, is distinct from these other normative properties.

That, in short, is my answer to the first question, namely the question what the nature of the standard of correctness for belief is. It might not seem like much of an answer. I have pointed to a more general property, of which correctness for belief is, I claim, an instance. I haven't given a reductive account of correctness for belief, or at least not one that will help anyone who lacks the notion of fittingness for attitudes in general. But a reductive account isn't the only way to characterise the nature of a property. We can point to various constitutive features it has, and to connections between it and other properties. I have tried to say a few things of this sort about fittingness, and I will say a few more below as I turn to the second question: how does correctness for belief explain epistemic reasons?

Reasons and Reasoning. My answer to the second question does not follow from my answer to the first, but it goes naturally with it. It is this: the standard of correctness for belief can explain why evidence for $\underline{\underline{ }}$ is a reason to believe $\underline{p}$ because it is a standard of fittingness, and what it $i s$ to be a reason is explained in terms of fittingness. I will now sketch an account of reasons to fill out this suggestion. ${ }^{15}$

Reasons, plausibly, are closely connected to reasoning. They are the sort of thing that it is suitable to reason with. It is natural to think that this is a constitutive truth about reasons. This suggests that we can understand reasons as, roughly, premises of good reasoning (Setiya 2014; Way m.s.; McHugh and Way m.s.). As I will explain later, it is plausible that good reasoning can be understood in terms of fittingness.

Focusing on reasons for belief, then, I propose that

(RR) For the fact that $\underline{p}$ to be a reason to believe $q$ is for $\underline{p}$ to be a premise of a good pattern of reasoning leading from fitting responses to the belief that $q$.

Some clarifications are in order.

I assume that reasons are facts. I think that everything could be reformulated satisfactorily under the assumption that reasons are mental states or contents. But I won't argue for this.

\footnotetext{
${ }^{15}$ Here I differ from 'buck-passers' who explain fittingness in terms of reasons (e.g. Schroeder 2010). Again, my claim here has affinities with Thomson (2008), but I do not accept her view that all reasons should be understood as reasons for believing.
} 
I take reasoning to be a kind of transition between attitudes, or between responses more generally. We can call the responses from which you make the transition the 'premiseresponses', and the response to which you make the transition the 'conclusion-response'. ${ }^{16}$ You might make a transition from the intention to go on holiday, and the belief that in order to go on holiday you must buy tickets, to the intention to buy tickets. This is a piece of reasoning with an intention and a means-end belief as premise-responses, and an intention to take the means as a conclusion-response.

In the case we're focusing on, the transition is to a belief, and typically from beliefs. For example, you might reason from the belief that the dog didn't bark, and the belief that the dog barks at strangers, to the belief that the dog knew the killer. We can call reasoning to beliefs 'theoretical reasoning'.

By a 'premise' of reasoning, I mean the content of a belief that is among the premiseresponses of that reasoning. ${ }^{17}$ Above, that the dog didn't bark, and that it barks at strangers, are premises of your reasoning.

$\mathrm{RR}$ is incomplete, in so far as all reasons are reasons for some agent or other, and RR doesn't say what relation the fact that $\underline{p}$ must stand in to a given agent, in order for it to be a reason for that agent. I won't say much about this, except to insist, first, that the reasoning in question need not be carried out. Patterns of reasoning are abstract. So the suggestion is $\underline{n o t}$ that all reasons correspond to actual episodes of reasoning. Second, the agent may not need to have the beliefs that are the premise-responses of the reasoning. Arguably the fact that $\underline{p}$ can be a reason for you to believe $q$, even though you do not believe $\underline{p}$.

RR says that reasons are premises of good reasoning from fitting responses - for example, from true beliefs. The motivation for this is easy to see. When a piece of reasoning starts from a bad place, it won't correspond to reasons, even if the transition itself is fine. Suppose that the dog in fact did bark. In that case, the reasoning described above is still good, but the fact that the dog barks at strangers is no reason to believe that the dog knew the killer.

RR appeals to the notion of good patterns of reasoning. Theoretical reasoning, like other reasoning, falls into patterns. Some patterns, like the one corresponding to modus ponens, are good. Others, like affirming the consequent, are bad. What is it for a pattern of reasoning to be good? It seems that good theoretical reasoning has something to do with getting you from true beliefs to other true beliefs. Roughly put, good patterns of theoretical reasoning are patterns that are truth-preserving, normally or other things equal.

True belief is correct, or fitting. Good theoretical reasoning preserves truth. Surely these facts have something to do with each other. I suggest that truth-preserving theoretical patterns are good because they preserve fittingness. ${ }^{18}$

This generalises to a plausible account of good reasoning as such. The point of reasoning is to keep you on track - to get you from the right sort of starting points to the right sort of finishing points. The case of theoretical reasoning strongly suggests that 'the right sort' is

\footnotetext{
${ }^{16}$ Reasoning need not conclude in exactly one response; it might conclude in more than one, or in withholding a response. I will address the latter case in the next section.

${ }^{17}$ This notion of a premise might need to be extended to include the contents of perceptual experiences or other 'seemings' (McHugh and Way m.s.).

${ }^{18}$ Couldn't a defender of the prescriptive or evaluative view say that good reasoning preserves permission or value rather than fittingness, and take on board the idea that reasons are premises of good reasoning? Yes, but my objections to those views, appropriately formulated, would still apply.
} 
fitting responses. So, in general, good patterns are those that preserve fittingness. To return to a non-theoretical example: if it is fitting to intend to go on holiday, and fitting to believe (i.e. true) that, in order to go on holiday, you must buy tickets, then it will also be fitting to intend to buy tickets.

So, using ' $\underline{P}$ ' to denote a premise-response, ' $\underline{C}$ ' a conclusion-response, and '>' the transition between them, we can say that

(GF) For it to be the case that $\left\{\underline{P}_{\underline{1}}, \ldots, P_{n}\right\}>\underline{C}$ is a good pattern of reasoning is for it to be the case that, normally, when $\left\{\underline{P}_{\underline{l}} \ldots, P_{n}\right\}$ are fitting, so too is $\underline{C}$.

'Normally' here stands in for a clause to deal with defeasible reasoning and reasons. The idea is that, for example, good inductive or abductive reasoning preserves truth in normal cases. I will not try to spell this out here. RR and GF may also require various other refinements (McHugh and Way m.s.). I will return to one of them below. My aim here is just to motivate and set out the main tenets of an account.

RR and GF constitute my answer to the question how the standard of correctness for belief explains epistemic reasons. This could be extended to other epistemic norms, by appeal to principles linking other normative properties to the property of being a reason. In sec. III I mentioned such principles for $\underline{\text { ought }}$ and $\underline{\text { may }}$.

\section{VII}

Attractions of the Fittingness View. The view I have outlined does well by our two desiderata. Regarding D1, the view understands epistemic normativity as a species of the genus of normativity for attitudes, and fits into a unified and plausible general picture of how normative notions like those of reasons, fittingness, ought and value hang together (McHugh and Way m.s.). It also refrains from arbitrarily taking correctness for belief to be explained in terms of some seemingly different property.

The view satisfies D2, and does so in an elegant way. It follows from RR and GF that, while good evidence for $\underline{p}$ will be a reason to believe $\underline{p}$, practical considerations are not genuine reasons for belief at all. From the belief that a reliable measurement showed you to be six foot tall, you can make a fittingness-preserving transition to the belief that you are six foot tall. So, if the reliable measurement really did show this, then that fact is a reason to believe that you are six foot tall. But, from the belief that it would make you feel good to believe that you are six foot tall, and the desire to feel good, you cannot make a fittingness-preserving transition to having that belief. It may very well be fitting to believe that this belief would make you feel good, and to desire to feel good, without its being fitting to believe (i.e. true) that you are six foot tall.

Practical considerations will give reasons for wanting to have certain beliefs, and, perhaps, for intending to bring them about. But, on this view, they won't give reasons for those beliefs. These claims are not novel. But it is an advantage of the present account that they fall out of it and are given a plausible explanation. D2 is thus satisfied. 
For reasons of space, I'll deal with just two objections to the view. ${ }^{19}$

\section{VIII}

Insufficiency of Truth-Preserving Patterns? Consider these two transitions:

Belief that grass is green $\quad>\quad$ Belief that 79 is prime;
Belief that 77 is prime $\quad>\quad$ Belief that grass is blue.

(F) Belief that 77 is prime $\quad>\quad$ Belief that grass is blue.

Both of these transitions instantiate truth-preserving patterns. Since it's necessarily true that 79 is prime, it's trivially the case that, normally, if it's true that grass is green then it's true that 79 is prime. Since it's necessarily false that 77 is prime, it's trivially the case that, normally, if it's true that 77 is prime then it's true that grass is blue. But surely the fact that grass is green is not a reason to believe that 79 is prime. And surely neither T nor F is good reasoning. So there seem to be counterexamples to the account.

My response to this objection starts from the observation that you cannot perform $\mathrm{T}$ or $\mathrm{F}$ competently, thereby adding the conclusion-belief to your stock of beliefs. To reason competently, not only must your reasoning instantiate the right sort of pattern - one that preserves fittingness - but you must also be appropriately sensitive to this fact. This is a familiar point. An agent might make transitions from beliefs in the axioms of arithmetic to beliefs in further propositions chosen at random, which happen to be theorems. This agent is not reasoning competently.

The transition in $\mathrm{T}$ is truth-preserving just because the conclusion is necessarily true; it has nothing to do with the premise. So, in order to be sensitive to the truth-preserving character of the transition, you must already be aware that the conclusion is necessarily true. So you can't competently come to believe the conclusion by performing $\mathrm{T}$.

Similarly, the transition in F is truth-preserving just because the premise is necessarily false; it has nothing to do with the conclusion. So, in order to be sensitive to the truth-preserving character of the transition, you must already be aware that the premise is necessarily false, and thus be sensitive to the fact that the transition (at least) might very well have a false conclusion. So you can't competently come to believe the conclusion by performing F. ${ }^{20}$

This suggests two possible ways of dealing with the objection, which I will not choose between.

We could accept that the fact that grass is green is a reason to believe that 79 is prime, but say that this is a useless reason: you cannot competently avail of it in coming to believe that 79 is prime. We could claim thereby to explain away intuitions to the effect that it is not a reason at all. Similarly, we might say, while $\mathrm{T}$ and $\mathrm{F}$ count as good reasoning, they are nonetheless useless bits of reasoning, since you can't competently extend your beliefs by performing them.

\footnotetext{
${ }^{19}$ For more, see McHugh and Way (m.s.).

${ }^{20}$ Similar points apply to transitions beginning from incompatible combinations of beliefs.
} 
Alternatively, we could revise the account of good reasoning:

$\left(\mathrm{GF}_{\mathrm{R}}\right)$ For it to be the case that $\left\{\underline{P}_{\underline{1}}, \ldots, P_{\underline{n}}\right\}>\underline{C}$ is a good pattern of reasoning is for it to be the case that you can come to hold $\underline{C}$ by competent reasoning from $\left\{\underline{P}_{1}, \ldots, P_{n}\right\}$.

Here, competence requires that your reasoning instantiate a fittingness-preserving pattern and that you perform it in a way that is sensitive to this.

IX

Reasons Not to Believe. You can have reasons not to believe things. Presumably an account of epistemic reasons should apply to these. But the account I offered doesn't obviously do so, since it's not clear that not believing can be fitting or unfitting. ${ }^{21}$

I think the spirit of my account accommodates reasons for not believing, and reasons for not doing things in general. The point of reasoning is not only to get you to fitting responses, but also to get rid of unfitting ones. But how can this be accommodated within the letter of the account?

Again, I see two broad options here, which I will sketch without choosing between them. Both options face prima facie objections, but I will indicate how these might be answered.

The first option is to say, using ' $\underline{E}$ ' to denote not holding $\underline{C}$, that

$\left(\mathrm{GN}_{1}\right)$ For it to be the case that $\left\{\underline{P}_{1} \ldots, P_{n}\right\}>\underline{E}$ is a good pattern of reasoning is for it to be the case that, normally, when $\left\{\underline{P}_{1} \ldots, P_{n}\right\}$ are fitting, $\underline{C}$ is unfitting. ${ }^{22}$

The problem with this is that, combined with RR suitably generalised, it seems to undergenerate reasons not to believe. In particular, it won't count weak evidence against $\underline{p}$ as a reason not to believe $\underline{p}$. The fact that the forecast said there might be rain is a reason not to believe that it will be dry. But it's not the case that, normally, when the forecast says there might be rain, it rains. So the transition from the belief that the forecast said there might be rain to not believing that it will be dry won't satisfy $\mathrm{GN}_{1}$.

The obvious way to answer this objection is to claim that the standard of fittingness for belief is not truth after all, but knowledge. The forecast saying that there might be rain stops you knowing that it will be dry, even if it in fact will. So it is not fitting to believe that it will be dry. So the transition to not believing that it will be dry satisfies $\mathrm{GN}_{1}$ after all.

In general, even weak counterevidence normally defeats knowledge. So, this move seems to get around the problem of undergeneration.

\footnotetext{
${ }^{21}$ Maybe reasons for not believing are really reasons for withholding belief, and maybe withholding belief can be fitting or unfitting. What would be the standard of fittingness for withholding? The obvious candidate is: not being in a position to know. If, as seems plausible to me, withholding and belief are never both fitting, it would follow that the standard of fittingness for belief is not truth, but, presumably, knowledge. This suggestion might thus end up being similar to my 'first option' below.

${ }^{22}$ This and the following principle could be reformulated on the model of $\mathrm{GF}_{\mathrm{R}}$ if necessary.
} 
Perhaps it's too controversial to claim that the standard of fittingness for belief is knowledge. Fortunately, there is a second option. We can say that

$\left(\mathrm{GN}_{2}\right)$ For it to be the case that $\left\{\underline{P}_{1} \ldots, \underline{P}_{n}\right\}>\underline{E}$ is a good pattern of reasoning is for it to be the case that $\left\{\underline{P}_{1} \ldots, P_{n}\right\}>\underline{C}$ is $\underline{\text { not }}$ a good pattern.

This has the opposite problem to $\mathrm{GN}_{1}$ : combined with $\mathrm{RR}$, it seems to overgenerate reasons not to believe. That's because, if $\left\{\underline{P}_{1} \ldots, P_{n}\right\}$ has nothing to do with whether $\underline{C}$ is fitting, $\left\{\underline{P}_{\underline{l}}, \ldots, \underline{P}_{\underline{n}}\right\}>\underline{C}$ won't be a good pattern, but nor, intuitively, will $\left\{\underline{P}_{\underline{l}}, \ldots, P_{n}\right\}>\underline{E}$. It's not good reasoning to move from the belief that grass is green to the belief that Hollande is president of France. But nor does it seem to be good reasoning to move from the belief that grass is green to $\underline{\text { not }}$ believing that Hollande is president. And the fact that grass is green doesn't seem to be a reason not to believe that Hollande is president. It seems irrelevant to it. My suggested response to this problem is to bite the bullet and accept that the fact that grass is green $\underline{i s}$ a reason not to believe that Hollande is president. This is not as bad as it sounds. Firstly, if all the evidence you have available about anything is that grass is green, then, presumably, you ought not believe that Hollande is president. Secondly, such reasons will be maximally weak: they will be outweighed whenever you have any reasons at all in the opposite direction.

To show this, I have to say something about outweighing. Let $\underline{p}$ be a reason to $\varphi$, and $q$ be a reason to $\psi$, where ping and $\psi$ ing are incompatible. Roughly, $\underline{p}$ outweighs $q$ when it's good reasoning to move from the belief that $\underline{p}$ and the belief that $q$ to $\varphi$ ing, but it's not good reasoning to move from this combination of beliefs to $\psi$ ing (Way m.s.).

Let $\underline{p}$ be any reason to believe that Hollande is president. So, from the belief that $\underline{p}$, perhaps together with other true beliefs, you can make a fittingness-preserving transition to the belief that Hollande is president. Now, consider the very same bit of reasoning, but with the belief that grass is green added to the premise-responses. This will still be fittingness-preserving, because the truth of the proposition that grass is green makes no difference to whether Hollande is president, or to the link between the evidence for his being president and his being so - that was what made it seem counterintuitive to suppose that it is a reason not to believe. So, this is good reasoning. So, by $\mathrm{GN}_{2}$, it is not good reasoning to move from this combination of beliefs to $\underline{\text { not }}$ believing that Hollande is president. Thus, the reason not to believe is outweighed by the reason to believe - which was an arbitrary stand-in for any such reason.

So, these intuitively irrelevant reasons not to believe are guaranteed to be defeated by any opposing reason. ${ }^{23}$ This doesn't quite make them useless, but it makes it unsurprising that we would ignore them and judge them not to be reasons at all. ${ }^{24}$

\footnotetext{
${ }^{23}$ As an audience member at the Aristotelian Society pointed out to me, there are reasons for belief that, because individually insufficient, will also come out as reasons not to believe, on the present account. For example, $\underline{p}$ might be a reason to believe $\underline{\&} \& q$, given appropriate further evidence. But it's not good reasoning to move from believing $\underline{p}$ alone to believing $\underline{\underline{a}} \& q$. So, given $\left(\mathrm{GN}_{2}\right)$, and (RR), $\underline{p}$ is also a reason not to believe $\underline{q} \& q$. Is this an unacceptable consequence?

If so, perhaps the account could be modified: $\underline{p}$ is a reason not to $\varphi$ only when it is not a (non-redundant) premise of a good pattern of reasoning leading from fitting responses to ping. But I am not sure it is unacceptable. Firstly, $p$ will be very weak as a reason not to believe $p \& q$, defeated by almost any reason to
} 
There is plenty more to be said about this and other matters. But I hope to have given some initial plausibility to the fittingness view. ${ }^{25}$

\author{
Philosophy \\ University of Southampton \\ Southampton SO17 1BF \\ C.McHugh@soton.ac.uk
}

\title{
References
}

Alston, William P. 2005: Beyond "Justification" : Dimensions of Epistemic Evaluation. Ithaca: Cornell University Press.

Boghossian, Paul A. 2003: 'The Normativity of Content'. Philosophical Issues, 13, pp. 31-45. BonJour, Laurence 1985: The Structure of Empirical Knowledge. Cambridge, Mass.: Harvard University Press.

Brentano, Franz 1889/1969: The Origin of Our Knowledge of Right and Wrong, trans. Oskar Kraus and Roderick M.Chisholm. London: Routledge.

Bykvist, Krister, and Hattiangadi, Anandi 2007: 'Does Thought Imply Ought?' Analysis, 67 (4), pp. 277-285.

Chappell, Richard Yetter 2012: 'Fittingness: The Sole Normative Primitive'. Philosophical Quarterly, 62 (249), pp. 684-704.

Dancy, Jonathan 2004: Ethics Without Principles. Oxford: Oxford University Press.

Fassio, Davide 2011: 'Belief, Correctness and Normativity'. Logique Et Analyse, 216, pp. 471-486.

Goldman, Alvin I. 1999: Knowledge in a social world. Oxford: Oxford University Press.

Kearns, Stephen, and Star, Daniel 2009: 'Reasons as Evidnce'. Oxford Studies in Metaethics, 4, pp. 215-242.

Lynch, Michael P. 2004: True to Life : Why Truth Matters. Cambridge, Mass.: MIT Press.

McHugh, Conor 2012: 'The Truth Norm of Belief'. Pacific Philosophical Quarterly, 93 (1), pp. 8-30.

McHugh, Conor, and Way, Jonathan m.s.: 'Fittingness First'.

Reisner, Andrew Evan, and Steglich-Petersen, Asbjørn (eds.) 2011: Reasons for Belief. Cambridge: Cambridge University Press.

Scanlon, Thomas 1998: What We Owe to Each Other. Cambridge, Mass.: Belknap Press of Harvard University Press.

believe it, including any reason given by $p$ itself. Secondly, in general it seems possible for the same consideration to be at once a reason for a belief and for not having that belief. Suppose $\underline{F} \mathrm{~s}$ are normally not $\underline{G} \mathrm{~s}$, but $\underline{H}$ s that are $\underline{F}$ s are normally $\underline{G}$ s. Then, that $\underline{x}$ is an $\underline{F}$ is a reason not to believe that $\underline{x}$ is a $\underline{G}$; but, if $\underline{x}$ is a $\underline{H}$, then, that $\underline{x}$ is an $\underline{F}$ is a reason to believe that $\underline{x}$ is a $\underline{G}$.

${ }^{24}$ For an argument that our intuitions about weak reasons are unreliable, see Schroeder (2007, Ch. 5).

${ }^{25}$ This paper contains ideas from collaborative work with Jonathan Way, and has benefited in many other ways from discussion with him. It has also benefited from discussion with Alex Gregory, Clayton Littlejohn, Daniel Whiting, and with audiences at the Universitat Autònoma de Barcelona, KU Leuven, University of Regensburg, University of Fribourg, University of Leeds, and the Aristotelian Society. This work was supported by the Arts and Humanities Research Council [grant number AH/K008188/1]. 
Schroeder, Mark 2007: Slaves of the Passions. Oxford: Oxford University Press.

Schroeder, Mark 2010: 'Value and the Right Kind of Reason'. Oxford Studies in Metaethics, 4, pp. 25-55.

Setiya, Kieran 2014: 'What is a Reason to Act?'. Philosophical Studies, 167 (2), 221-235.

Shah, Nishi 2003: 'How Truth Governs Belief'. Philosophical Review, 112 (4), pp. 447-482.

Smithies, Declan 2012: 'The Normative Role of Knowledge'. Nous, 46 (2), pp. 265-288.

Sosa, Ernest 2007: A Virtue Epistemology. Oxford: Oxford University Press.

Thomson, Judith Jarvis 2008: Normativity. Chicago, Ill.: Open Court.

Way, Jonathan 2013: 'Value and Reasons to Favour'. Oxford Studies in Methaethics, 8, 2749.

Way, Jonathan m.s.: 'Reasons as Premises of Good Reasoning.'

Wedgwood, Ralph 2002: 'The Aim of Belief'. Philosophical Perspectives, 16, pp. 267-97

Whiting, Daniel 2010: 'Should I Believe the Truth?' Dialectica, 64 (2), pp. 213-224.

Whiting, Daniel 2013: 'Truth: The Aim and Norm of Belief'. Teorema, 32 (3), 121-135.

Wiggins, David 1987: 'A Sensible Subjectivism?' In his Needs,Values, Truth: Essays in the Philosophy of Value. Oxford: Blackwell. 